\section{Revised 1990 estimates of maternal mortality: a new approach by WHO and UNICEF}

Source: World Health Organization and United Nations Children's Fund. Revised 1990 estimates of maternal mortality: a new approach by WHO and UNICEF. Geneva: WHO; April 1996. (Document WHO/ FRH/MSM/96.11; UNICEF/PLN/96.1).

\section{INTRODUCTION}

During the past decade, a number of international conferences established goals related to the environment, population and development, and health. The reduction of maternal mortality to half the 1990 levels by the year 2000 was a goal enunciated at several such conferences, including the Nairobi Safe Motherhood Conference (1987), the World Summit for Children (1990), the International Conference on Population and Development (1994), and the Fourth World Conference on Women (1995). The incorporation of maternal mortality reduction into the goals of the international community reflects its importance as a measure of human and social development.

Maternal mortality is a particularly sensitive indicator of inequity. Of all the indicators commonly used to compare levels of development between countries and regions, levels of maternal mortality show the widest disparities. Maternal mortality offers a litmus test of the status of women, their access to health care, and the adequacy of the health care system in responding to their needs. Information about the levels and trends of maternal mortality is needed, therefore, not only for what it reveals about the risks of pregnancy and childbirth, but also for what it implies about women's health in general and, by extension, their social and economic status.

Progress toward the goal is extremely difficult to ascertain for two reasons: maternal mortality is difficult to measure, and the information available at the country level does not generally permit the establishment of good baseline data. In order to address these problems, WHO and UNICEF have worked with experts from Johns Hopkins University (Baltimore, Maryland, U.S.A.) to develop a new approach for estimating levels of maternal mortality in developing countries. The new approach has the dual objective of generating improved estimates for countries with inadequate or no national data on maternal mortality, while at the same time providing better estimates of maternal mortality in 1990 as a baseline against which to measure progress.

\section{MEASURING MATERNAL MORTALITY}

Assessment of levels of maternal mortality at the national level requires knowledge about deaths 
of women of reproductive age (15-49 years), the cause of death, and also whether or not the woman was pregnant at the time of death or had recently been so. Broadly speaking, countries fall into one of three categories:

1. Countries with no reliable system of vital registration, where maternal deaths-like other vital events-go unrecorded;

2. Countries with relatively complete vital registration in terms of numbers of births and deaths but where cause of death is not adequately classified; cause of death is routinely reported in only 78 countries or areas, covering approximately $35 \%$ of the world's population (1).

3. Countries with complete vital registration and good cause of death attribution; even in these countries, misclassification of maternal deaths can arise for a variety of reasons.

Some innovative methodologies have been devised to overcome the absence of data in countries with poor or nonexistent vital registration. For example, maternal mortality can be measured by incorporating questions on pregnancy and deaths into large-scale households surveys. The disadvantage of such approaches is that they require large sample sizes in order to avoid high sampling error rates and thus are extremely expensive and timeconsuming (2). In general, countries with high maternal mortality do not have the resources to rely on surveys for data.

A more cost-effective approach is the "sisterhood method." In this method, existing household surveys incorporate a few simple questions about whether or not the sisters of the respondent are still alive. The advantage is that much smaller sample sizes are needed because each respondent can provide information on a number of sisters. The disadvantage is that the method does not provide a current estimate, but gives an idea of the level of maternal mortality roughly 10 years earlier. Furthermore, the methodology was developed for use where there are strong cultural ties among siblings (usually sisters) and where siblings could be expected to be fully aware of the vital events in each other's lives. Where such cultural ties are less strong, the method is likely to be less effective and may underestimate pregnancy-related mortality. Indeed, evidence is emerging that the sisterhood method may miss a sizable proportion of maternal deaths $(3,4)$.

The best way of measuring maternal mortality in the absence of vital registration is to identify and investigate the causes of all deaths of women of reproductive age - the "reproductive age mortality survey" (RAMOS). This method has been applied in countries with good vital registration systems to calculate the extent of misclassification (5), as well as in countries without vital registration of deaths. Multiple sources of information-civil registers, health facility records, community leaders, religious authorities, undertakers, cemetery officials, schoolchildren-are used to identify all deaths (6). Subsequently, interviews with household members and health care providers and reviews of facility records are conducted in order to classify deaths as maternal or otherwise (verbal autopsy).

Although RAMOS studies are considered to be the "gold standard" for estimating maternal mortality, they are also time-consuming and complex to undertake, particularly on a large scale. Because of the difficulties and costs involved, only 10 developing countries have carried out RAMOS or household studies to estimate maternal mortality at the national level. As a result, other methods have to be devised to provide broad estimates of the extent of the problem.

\section{DERIVATION OF THE ESTIMATES}

The earlier global and regional estimates of maternal mortality were developed by WHO using a model based on female life expectancy. Although they were generally well accepted and used by the international health community, they suffered from a major weakness. Because the model was greatly simplified and not very robust, $\mathrm{WHO}$ was unable to issue the individual country estimates from which the regional and global totals were calculated. Thus the model could not be used to provide an approximation of the level of maternal mortality in an individual country. ${ }^{1}$

The revised WHO and UNICEF estimates were developed using a dual strategy: existing national maternal mortality estimates were adjusted to account for underreporting and misclassification, and a simple model was developed to predict values for countries with no data. To predict maternal mortality, the model uses two widely available independent variables: general fertility rates and proportion of births that are assisted by a trained person. The definition of "trained person" encompasses doctors (specialized or not specialized) and persons with formally recognized midwifery skills, but excludes traditional birth attendants (TBAs), whether trained or not. The rationale is that TBAs generally cannot manage obstetric complications or perform lifesaving procedures needed to reduce maternal mortality.

\footnotetext{
In 1992 the individual country estimates were inadvertently issued in the Human Development Report 1992 (United Nations Development Program), but were never officially used by any UN agency.
} 
Maternal mortality estimates for individual countries fall into five groups:

1. Developed countries with complete vital registration systems and relatively good attribution of cause of death: For these countries the maternal mortality ratio is the reported number adjusted by a factor of 1.5 to account for the well-known problem of misclassification of maternal deaths. The 1.5 adjustment factor is based on evidence from several studies $(5,7)$.

2. Developing countries with good death registration but poor or nonexistent attribution of cause of death: The model is used to predict the proportion of deaths of women of reproductive age that are maternal. This proportion is then applied to the deaths of women of reproductive age actually registered to obtain the number of maternal deaths and the maternal mortality ratio.

3. Countries with RAMOS-type estimates of maternal mortality: The maternal mortality ratio derived from the RAMOS study is used directly without any adjustments.

4. Countries with sisterhood estimates of maternal mortality: Several recent studies have found that the sisterhood method underestimates total female adult mortality and, presumably, maternal mortality as well $(3,4)$. However, the sisterhood method, in addition to providing an estimate of maternal mortality, also provides estimates of the proportion of all deaths of women of reproductive age that are maternal. ${ }^{2}$ Therefore, for these countries, this proportion was applied to the total number of deaths of women of reproductive age generated by the United Nations Population Division's population projections (1994 revision) for the year 1990, since these figures are believed to be better estimates of female adult mortality.

5. Countries with no estimates of maternal mortality: For countries without accurate information on numbers of deaths and without direct or indirect estimates of maternal mortality, the model is used to predict the maternal proportion of all deaths of women of reproductive age. This proportion is applied to the 1990 United Nations projections of adult female deaths to derive the maternal mortality ratio.

\footnotetext{
2 Insofar as the sisterhood method identifies all deaths during pregnancy, which may include some due to fortuitous or accidental causes, it may overestimate maternal mortality. However, the method is likely to miss some early maternal deaths, such as those related to abortion or ectopic pregnancy. It has been assumed that the two biases cancel out.
}

\section{NEW ESTIMATES OF MATERNAL MORTALITY}

The results of the new approach indicate that, worldwide, there are some 585000 maternal deaths annually, $99 \%$ of them in developing countries. This figure is around 80000 deaths more than earlier estimates had suggested and indicates a substantial underestimation of maternal mortality in the past.

In developing countries, maternal mortality ratios range from 190 per 100000 live births in Latin America and the Caribbean to 870 per 100000 in Africa. Extremely high ratios (exceeding 1000 per 100000 live births) are found in some of the countries of eastern and western Africa.

The maternal mortality ratios derived from this new approach differ from earlier estimates both in terms of global numbers of maternal deaths and in terms of the regional breakdowns. In particular, the new estimates for Africa are generally much higher, whereas those for Asia and Latin America as a whole are broadly comparable to the earlier figures (Table 1). The estimates also differ-in some cases considerably-from official figures or from figures derived from other sources, such as sisterhood studies.

\section{Ways the new estimates can be used}

This new approach is primarily intended to be of use in countries with no estimates of maternal mortality or where there is concern about the adequacy of officially reported estimates. The intention was to draw attention to the existence and likely dimensions of the problem of maternal mortality. The estimates should be taken as indicating orders of magnitude rather than precise numbers and are not necessarily what governments consider most appropriate. The results for each country should serve as a stimulus for action and for the mobilization of national and external resources to that end. The nature of such action will be determined in large measure by the social and economic conditions of the country, but it must include increasing all women's access to high-quality care during pregnancy and childbirth.

\section{Ways the estimates should not be used}

The standard errors associated with the predicted maternal mortality ratios are very large. Therefore, they cannot be used to monitor trends on a year-to-year basis, but may be used to monitor changes over the decade. The figures pertain to the 
TABLE 1. New regional estimates of maternal mortality compared with previous estimates

\begin{tabular}{|c|c|c|c|c|}
\hline \multirow[b]{2}{*}{ UN region } & \multicolumn{2}{|c|}{$\begin{array}{l}\text { Maternal mortality ratio } \\
\text { (maternal deaths per } 100000 \text { live births) }\end{array}$} & \multicolumn{2}{|c|}{ Maternal deaths (1 000s) } \\
\hline & Old estimates & New estimates & Old estimates & New estimates \\
\hline World total & 370 & 430 & 509 & 585 \\
\hline More developed regions ${ }^{a}$ & 26 & 27 & 4 & 4 \\
\hline Less developed regions & 420 & 480 & 505 & 582 \\
\hline Africa & 630 & 870 & 169 & 235 \\
\hline Eastern & 680 & 1060 & 60 & 97 \\
\hline Middle & 710 & 950 & 21 & 31 \\
\hline Northern & 360 & 340 & 17 & 16 \\
\hline Southern & 270 & 260 & 4 & 3.6 \\
\hline Western & 760 & 1020 & 66 & 87 \\
\hline Asia $^{\mathrm{a}}$ & 380 & 390 & 310 & 323 \\
\hline Eastern & 120 & 95 & 30 & 24 \\
\hline South-central & $(570)^{b}$ & 560 & $(224)^{b}$ & 227 \\
\hline South-eastern & 340 & 440 & 42 & 56 \\
\hline Western & 280 & 320 & 12 & 16 \\
\hline Europe & $(23)^{b}$ & 36 & $(1)^{b}$ & 3.2 \\
\hline Latin America and the Caribbean & 200 & 190 & 25 & 23 \\
\hline Caribbean & 260 & 400 & 2 & 3.2 \\
\hline Central America & 160 & 140 & 6 & 4.7 \\
\hline South America & 220 & 200 & 17 & 15 \\
\hline North America & 12 & 11 & 1 & 0.5 \\
\hline Oceania $^{c}$ & 600 & 680 & 1 & 1.4 \\
\hline
\end{tabular}

year 1990 and should be seen as a recalculation of the earlier 1991 revision rather than as indicative of trends since then.

\section{Interagency collaboration}

These new maternal mortality figures will be used by all the agencies of the United Nations system in their work, including the United Nations Population Fund (UNFPA), the United Nations Development Program (UNDP), the United Nations Population Division and Statistical Division, and the World Bank. The new approach was developed by Cynthia Stanton and Kenneth Hill of Johns Hopkins University. A detailed description of the methodology has been published (4). The work was guided throughout by an informal advisory group made up of members from the above-mentioned UN agencies as well as nongovernmental organizations working to reduce maternal mortality, notably the Population Council, Family Health International, MotherCare, the Columbia University School of Public Health, the London School of Hygiene and Tropical Medicine, and the Dugald Baird Center for Women's Health. WHO and UNICEF are grateful to all the individuals whose time and commitment contributed greatly to the process.

\section{OTHER METHODS FOR MONITORING TRENDS}

Where current vital registration systems underestimate maternal mortality because of misclassification of maternal deaths, estimates can be improved through the establishment of a system of confidential inquiries. Such inquiries not only result in better knowledge of the dimensions of the problem but also, insofar as they identify the causes of misclassification and analyze the management of each case, lead directly to improvements in case management and reductions in substandard care (8).

For monitoring progress toward the year 2000 goals, UNICEF and WHO propose process indicators which describe the causal pathways leading to maternal deaths and examine the coverage and quality of services for the management of obstetric complications (9). Process indicators can help to identify the most appropriate mix of interventions and to assess progress towards improved coverage and quality of care. 
UNICEF and WHO are currently developing guidelines on the use of such process indicators at the country level. The use of these indicators does not imply the abandonment of efforts to measure impact-that is, maternal mortality ratios. However, it is unrealistic to expect that all countries will be able to establish the kind of ongoing monitoring systems needed for a regular appraisal of maternal mortality. Nor would it be appropriate to direct scarce resources to such an undertaking at the expense of programs to deal with the problem at its source.

\section{THE NEXT STEPS}

Despite its limitations in terms of monitoring, this approach represents a substantial improvement on earlier efforts to estimate maternal mortality at regional and global levels, but even more so at the national level. At regular intervals, WHO and UNICEF will update and expand the data set and calculate new estimates of maternal mortality.

The use of such strategies to estimate maternal mortality is a short-term solution to the problem of measurement. In the long term, accurate information about maternal mortality is dependent on improvements in vital registration systems and their incorporation into all national health information systems. This must be the ultimate objective of all national authorities and of multilateral and bilateral development agencies.

\section{SINOPSIS}

\section{Estimaciones revisadas de la mortalidad materna en 1990: nuevo método de la OMS y el UNICEF}

La Organización Mundial de la Salud (OMS) y el Fondo de las Naciones Unidas para la Infancia (UNICEF) han desarrollado un método nuevo para estimar los niveles de mortalidad materna. Las estimaciones para 1990 efectuadas previamente, que están basadas en un modelo muy simplificado, existían únicamente para las distintas regiones y el mundo en su totalidad, pero no para países individuales. El modelo nuevo permite hacer estimaciones nacionales y regionales, tanto para países sin datos disponibles como para los que tienen datos de alcance nacional en una variedad de fuentes. En términos generales, las nuevas estimaciones (que representan un cálculo nuevo de las estimaciones ya efectuadas para 1990, y no cifras correspondientes a un año posterior) indican que en el pasado ha habido una subestimación notable de la mortalidad materna, especialmente en ciertas partes del África. Las nuevas cifras servirán de referencia para medir el progreso hacia la meta de reducir la mortalidad materna, para el año 2000, a la mitad de la que había en 1990. Esta meta ha sido respaldada por numerosas conferencias internacionales en la última década.

\section{REFERENCES}

1. World Health Organization. Cause of death statistics and vital rates, civil registration systems and alternative sources of information. In: World Health Statistics Annual 1993. Geneva: WHO; 1994: A/B-3-31.

2. Kwast BE, Kidane-Mariam W, Saed EM, Fowkes FG. Epidemiology of maternal mortality in Addis Ababa: a community-based study. Ethiop Med J 1985; 23:7-16.

3. Shahidullah M. The Sisterhood Method of estimating maternal mortality: the
Matlab experience. Stud Fam Plann 1995; 26:2: 101-106.

4. Stanton C, et al. Modelling maternal mortality in the developing world. 1996.

5. Bouvier-Colle MH, Varnoux N, Costes P, Hatton F. Reasons for the underreporting of maternal mortality in France, as indicated by a survey of all deaths of women of childbearing age. Int J Epidemiol 1991; 20:717-721.

6. Walker GJ, Ashley DE, McCaw AM, Bernard GW. Maternal mortality in Jamaica. Lancet 1986;1(8479):486-488
7. Atrash HK, Alexander S, Berg CJ. Maternal mortality in developed countries: not just a concern of the past. Obstet Gynecol 1995;86:700-705.

8. United Kingdom, Department of Health. Report on confidential enquiries into maternal deaths in England and Wales 1982-1984. London: HMSO; 1989.

9. United Nations Children's Fund, World Health Organization. Maternal mortality: guidelines for monitoring progress. 2nd ed. Geneva: UNICEF, WHO; 1996. 